Military Technical College Kobry El-Kobbah, Cairo, Egypt

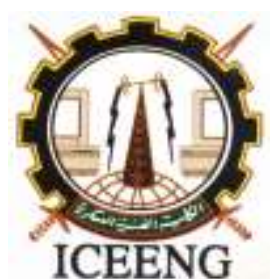

\section{$11^{\text {th }}$ International Conference on Electrical Engineering ICEENG 2018}

\title{
ENERGY SAVING POTENTIAL USING SCOTOPICALLY ENHANCED LIGHTING
}

Ragad Khaled Kheireldin*, Saida Khalaf*, Kamelia Youssef*, and Ibrahim Yassin*

\begin{abstract}
Start Light Emitting Diodes (LEDs) had been profiting a great deal of interest in the last few years. LED bulbs are much more efficient, contain no toxic materials, eco-friendly, consume less energy, directional lighting, quick to turn on, and dimmable models. Scotopically Enhanced Lighting (SEL) is lighting that has more bluer in the spectrum, typically characterized by higher correlated color temperature (CCT). LED light provides better visual acuity, enhanced brightness perception, and produces a light spectrum more closely resembling daylight. Therefore, the SEL can be used at lower energy levels while maintaining equal vision. The functioning factor used on SEL is called the S/P ratio; it is equal to the proportion of scotopic to photopic lumens from a lighting source. LEDs having different values for CCT, and higher S/P ratio, can be used to describe the effective lumens of indoor lighting. Using SEL, LEDs have achieved high energy savings by advocating the use of bluer lighting in commercial and municipal buildings. This paper focuses specifically on the SEL applications and recommends replacing existing traditional lamps by LED lamps having higher CCT.
\end{abstract}

\section{KEY WORDS}

State Scotopic, photopic, light emitting diode, color temperature, energy saving, compact fluorescent lamp, S/P ratio.

\section{NOMENCLATURE}

P: Photopic quantity.

Ra: Color rendering index

S: Scotopic quantity.

VE: Visual Equivalence.

* Improving Energy Efficiency of Lighting \& Building Appliances Project. Cairo, Egypt. 


\section{INTRODUNTION}

The Ministry of Electricity and Renewable Energy (MERE), within its strategy, fully aligned with the Egyptian Government commitment to energy efficiency (EE) in different sectors of economy, is currently implementing the "Improving Energy Efficiency of Lighting and Building Appliances" (IEEL \& A) Project which is a national executed project funded by the United Nations Development Program (UNDP), the Global Environment Facility (GEF) and the Egyptian Government. The objective of the project is to improve the EE of end-use equipment, specifically building appliances and lighting systems manufactured, marketed and used in Egypt in order to facilitate a comprehensive market transformation of the Egyptian market towards the use of more EE lighting systems and electrical appliances.

In Egypt, lighting represents more than $16 \%$ of the total electricity consumption at the national level; therefore, the project among its activities has taken an initiative to demonstrate the techno-economic feasibility of implementing EE lighting projects in different types of existing buildings by replacing inefficient lighting systems by efficient ones aiming to promote replication and expansion on the national level.

To encourage building owners/managers adopting these initiatives, the project is providing no cost technical assistance that includes, low energy, an energy audit followed by a techno economic prefeasibility study with different alternative options, and recommendation for implementation, then taking the decision of implementation, the project is also providing the beneficiaries with technical specifications of high efficient lighting systems, a list of recommended suppliers of efficient lighting systems, assisting in monitoring and verification of realized energy savings, cost savings, $\mathrm{CO}_{2}$ reduction.

IEEL\&A implemented a number of specific activities in Cairo and Alexandria such as public building and street lighting, to use LED technologies, promote EE practices and see energy and financial savings.

\section{SCOTOPICALY ENHANCED LIGHTING (SEL)}

The eye has a large dynamic wide, it can operate in the bright lit, and effectively becomes a photon counter in very dim lit. Enabling this wide range are different visual responses to light levels of the human eye. There are three main modes of vision, each of which uses the eye's complementary sensors of: cone cells, rod cells, or a combination of both.

Cone cells are the dominant visual receptor under daylight and lit interior conditions (known photopic conditions). Rod cells are dominant under dark and low light conditions (known scoptopic conditions). Under medium lighting conditions, a combination of cones and rods are required (known mesopic conditions).

Table 1 summarizes the properties of photopic and scotopic. SEL, using certain lamps containing more blue in the spectrum, will be more visually efficient than lamps with less scotopic content, in spite of, they have the same lumen (photopic) and efficacy values. The SEL can be used at lower energy levels while maintaining equal vision. 
Table 1. Properties of photopic and scotopic

\begin{tabular}{|c|c|}
\hline \multicolumn{2}{|c|}{ Properties of Photopic and Scotopic } \\
\hline Photopic & Scotopic \\
\hline $\begin{array}{r}\text {-Known as light or daylight } \\
\text { vision. } \\
\text {-Based on the sensitivity of } \\
\text { cone cell. } \\
\text {-Allows seeing different colors. } \\
\text {-Peak sensitivity towards red } \\
\text { (550nm). } \\
\text {-Photopic range: } 6 \text { to } 7 \text { million } \\
\text { cones. } \\
\text {-Higher sensitivity as the light } \\
\text { is brighter. } \\
\text {-Basis for modern photometry } \\
\text { (light metering). }\end{array}$ & $\begin{array}{r}\text {-Known as dark or night } \\
\text { vision. } \\
\text {-Based on the sensitivity of } \\
\text { rod cells. } \\
\text {-Peak sensitivity towards blue } \\
(500 \mathrm{~nm}) . \\
\text {-Scotopic range: } 120 \text { million } \\
\text { rods. } \\
\text {-Higher sensitivity and speed } \\
\text { in different spectral range. } \\
\text {-Higher color temperature } \\
\text { lamps } 5000^{\circ} \mathrm{K}-7000^{\circ} \mathrm{K}\end{array}$ \\
\hline
\end{tabular}

\section{S/P RATIO}

Scotopic and photopic is the amount of light registered by the rod cells and the cone cells of the human eye. The factor $S / P$ is the ratio of scotopic luminous quantity to photopic luminous quantity for lamp spectral power distribution. From a given photopic quantity $(P)$, the analogous scotopic quantity $(S)$ can be found by multiplying $P$ by $S / P$ ratio, (e.g. natural daylight has an S/P ratio close to 2.5 which means that it is highly scotopically enriched).

Typical S/P values for most lamps vary from 1 to 2.3 , except for HPS and LPS lamps which have $S / P$ values of 0.6 and 0.4 respectively. Using light with high $S / P$ ratio, the big blue part of the light goes to a smaller pupil size. This smaller pupil size goes to a bigger focus depth. This has a good effect on tasks that need a lot of visual systems for immediate reading, fixing goods, analyzing goods ... etc.

Each light source has S/P ratio matched with its correlated color temperature (CCT), lamps with higher CCTs naturally emit more light in the blue part of the spectrum, that helps classify its effectiveness for SEL.

Table 2 shows S/P ratio range associated with CCT for LED lamps. Also, some common $\mathrm{S} / \mathrm{P}$ ratios are listed in table 3.

Table 2. S/P ratios versus CCT for led lamps [8]

\begin{tabular}{|c|c|}
\hline S/P range & $\boldsymbol{C C T}_{\left(\text {in }^{\mathbf{}} \boldsymbol{K}\right)}$ \\
\hline $1.1-1.4$ & 2700 \\
\hline $1.2-1.5$ & 3000 \\
\hline $1.3-1.6$ & 3500 \\
\hline $1.4-1.8$ & 4000 \\
\hline $1.6-2.0$ & 5000 \\
\hline $1.9-2.2$ & 6000 \\
\hline
\end{tabular}


Table 3. Common S/P ratio versus CCT for led lamps [9]

\begin{tabular}{|c|c|}
\hline $\mathbf{S} / \boldsymbol{P}$ & $\boldsymbol{C C T}\left(\right.$ in $\left.^{\mathbf{}} \boldsymbol{K}\right)$ \\
\hline 1.4 & 3000 \\
\hline 1.65 & 4000 \\
\hline 2.1 & 5000 \\
\hline
\end{tabular}

\section{VISUALLY EFFECTIVE LUMENS (VE)}

- Photometric devices and light meters are generally calibrated to the cone spectral sensitivity (photopic response).

- The light output of lighting source (lumens) is rated only in terms of its photopic content.

- The photopic lumens do not tell the whole thing of a lamp's effectiveness.

- The higher S/P ratio, the more scotopic lumens are produced at a given CCT.

Each light source has an S/P ratio associated with its color temperature, which supports to classify its effectiveness for SEL, the higher the S/P ratio, the more scotopic lumens are generated at a given CCT.

In fact, there is no one S/P ratio that applies equally to all lighting applications, so several studies [1] to [5], have proposed using the following formula to establish visual equivalence for various situations.

$$
V E=P(S / P)^{n}
$$

Where $n$ is a value between 0.0 and 1.0 .

Each activity has a recommended $n$ value related to it. To build ambient lighting depending on the S/P ratio, table 4 is considered.

Table 4. Visually effective lumens (VE)

\begin{tabular}{|c|l|}
\hline \multicolumn{1}{|c|}{ Equation } & \multicolumn{1}{c|}{ Description } \\
\hline $\mathrm{VE}=\mathrm{P}(\mathrm{S} / \mathrm{P})^{0.5}$ & $\begin{array}{l}\text {-VE measurements based on Brightness perception } \\
\text { (in lumens) } \\
\text {-From [1] a rough estimate can be made of where } \\
\text { brightness equality would occur. }\end{array}$ \\
\hline $\mathrm{VE}=\mathrm{P}(\mathrm{S} / \mathrm{P})^{0.78}$ & $\begin{array}{l}\text {-Veading. } \\
\text { rearements based on Visual Acuity for paper } \\
\text {-Empirically in laboratory studies. Also it is the } \\
\text { approximation of the decreased pupil size. }\end{array}$ \\
\hline
\end{tabular}




\begin{tabular}{|l|l|}
\hline$V E=P(S / P)$ & $\begin{array}{l}\text {-VE measurements based on Visual Acuity for } \\
\text { computer tasks. } \\
\text {-The best compromise for ambient lighting is to } \\
\text { provide the smallest pupils with the least amount of } \\
\text { glare. This means that the ambient lighting needs to } \\
\text { be judged purely on the basis of its scotopic content }\end{array}$ \\
\hline
\end{tabular}

\section{SAVING ENERGY WITH SPECTRALLY ENHANCED LIGHTING}

In several scientific studies [1] to [5] recommendations are:

- Existing lamps be replaced with lower wattage lamps having a higher correlated color temperature (CCT).

- Lamps, with higher CCTs, naturally emit more light in the blue part of the spectrum.

The energy savings made possible by SEL rely on a lighting concept "visual equivalence" which define each light source a weighted ratio of scotopic and photopic lumens output.

More efficient sources with higher S/P ratio, such as LEDs, would yield even better results related to the potential cost and energy savings. $\mathrm{Ra}$ is color rendering index.

\section{CASE STUDY}

The existing building standard lamps had a CCT of $3500{ }^{\circ} \mathrm{K}$. The common types of lamps are incandescent, compact fluorescent lamp (CFL), fluorescent tube and halogen spot. Lighting modification consisted of retrofitting existing luminaries with new LED lamps without affecting the optical systems of the fixture.

The light output (lumens) of lamps and the correlating measure of lighting efficacy $(\mathrm{lm} / \mathrm{w})$ are based solely on the photopic weighting function. Phosphors used of lamps are mixed specifically to try to make lamps of equal wattage and operating characteristics have approximately the same photopic lumen output, so that the overall lamp efficacy is generally the same regardless of the lamp color, for example, one lamp will have approximately the same lumen and efficacy values for $3000 \mathrm{~K}, 3500{ }^{\circ} \mathrm{K}, 41000 \mathrm{~K}$, and 5000 K.

Tables 5, 6, 7 summarize the measured CCT, lumen and Ra for different manufacture LED bulbs, rating $4 \mathrm{~W}, 6 \mathrm{~W}$ and $9 \mathrm{~W}$ respectively.

Table VIII shows a method model for SEL based on the relation in table 4 shows a case study for how the lumen ratings of $4 \mathrm{~W}$ lamps can be modified for specific tasks using the $\mathrm{S} / \mathrm{P}$ ratio.

Table 9 summarizes the percentage of potential energy savings using VE lumen rating by comparing the $4 \mathrm{~W}$ LED bulbs have $2700{ }^{\circ} \mathrm{K}$ and $4100{ }^{\circ} \mathrm{K}$. Specifically, the $4100{ }^{\circ} \mathrm{K} \mathrm{SEL}$ demonstrates potential energy savings ranging from $5.2 \%$ to $14 \%$ compared to $2700 \mathrm{KK}$ lamps. 
Table 5. Measured parameters for $4 \mathrm{~W}$ led lamps

\begin{tabular}{|c|c|c|c|}
\hline $\begin{array}{c}\text { Sample } \\
\text { no. }\end{array}$ & $\boldsymbol{C C T}(\boldsymbol{K})$ & $\begin{array}{c}\text { Lumen(P) } \\
(\mathbf{I m})\end{array}$ & $\boldsymbol{R} \boldsymbol{a}$ \\
\hline 1 & 3936 & 357 & 84 \\
\hline 2 & 3945 & 326 & 85.6 \\
\hline 3 & 3980 & 356 & 85.2 \\
\hline 4 & 4013 & 302 & 84.7 \\
\hline 5 & 4046 & 304 & 85 \\
\hline 6 & 4201 & 390 & 82.5 \\
\hline 7 & 4252 & 391 & 83.3 \\
\hline 8 & 4461 & 319 & 91.6 \\
\hline 9 & 4985 & 435 & 82.9 \\
\hline 10 & 4994 & 422 & 82.7 \\
\hline 11 & 5160 & 359 & 86 \\
\hline 12 & 5256 & 402 & 85.4 \\
\hline 13 & 5324 & 393 & 85.7 \\
\hline 14 & 5547 & 392 & 91.1 \\
\hline 15 & 6763 & 374 & 84.4 \\
\hline
\end{tabular}

Table 6. Measured parameters for $6 \mathrm{~W}$ led lamps

\begin{tabular}{|c|c|c|c|}
\hline $\begin{array}{c}\text { Sample } \\
\text { no. }\end{array}$ & $\boldsymbol{C C T}(\boldsymbol{K})$ & $\begin{array}{c}\text { Lumen(P) } \\
(\mathbf{I m})\end{array}$ & $\boldsymbol{R a}$ \\
\hline 1 & 4062 & 545 & 82.2 \\
\hline 2 & 4851 & 595 & 81.9 \\
\hline 3 & 4921 & 610 & 95.3 \\
\hline 4 & 4974 & 558 & 82.7 \\
\hline 5 & 4984 & 595 & 82.8 \\
\hline 6 & 5147 & 488 & 85.3 \\
\hline 7 & 5190 & 640 & 85.8 \\
\hline 8 & 7265 & 638 & 97.2 \\
\hline 9 & 7534 & 609 & 90.5 \\
\hline
\end{tabular}

Table 7. Measured parameters for $9 \mathrm{~W}$ led lamps

\begin{tabular}{|c|c|c|c|}
\hline $\begin{array}{c}\text { Sample } \\
\text { no. }\end{array}$ & $\boldsymbol{C C T}(\boldsymbol{K})$ & $\begin{array}{c}\text { Lumen(P) } \\
(\mathbf{I m})\end{array}$ & $\boldsymbol{R a}^{*}$ \\
\hline 1 & 4541 & 998 & 87.9 \\
\hline 2 & 4870 & 918 & 82.3 \\
\hline 3 & 4905 & 901 & 83.9 \\
\hline 4 & 5717 & 814 & 93.4 \\
\hline 5 & 6393 & 905 & 83.5 \\
\hline
\end{tabular}


Table 8. Visually effective lumens and efficiencies using the S/P ratio for $4 W$ LED

\begin{tabular}{|c|c|c|c|c|c|c|c|c|c|c|}
\hline \multirow{2}{*}{ No } & \multirow{2}{*}{$\begin{array}{c}P \\
(I m)\end{array}$} & \multirow{2}{*}{$\operatorname{Im} / W$} & \multirow{2}{*}{${ }^{0} \mathrm{~K}$} & \multirow{2}{*}{$S / P$} & \multicolumn{2}{|c|}{$P(S / P)^{0.5}$} & \multicolumn{2}{|c|}{$P(S / P)^{0.78}$} & \multicolumn{2}{|c|}{$P(S / P)$} \\
\hline & & & & & Im & $\operatorname{Im} / W$ & Im & $\operatorname{Im} / W$ & Im & $\operatorname{Im} / W$ \\
\hline 1 & 470 & & & & 548 & 137 & 597 & 149 & 639 & 160 \\
\hline 2 & 450 & 112.5 & 4100 & 1.65 & 578 & 145 & 665 & 166 & 743 & 186 \\
\hline
\end{tabular}

Table 9. Percentage of potential energy savings comparing the led lamps no (2) to no (1) in table (8)

\begin{tabular}{|c|c|c|}
\hline $\begin{array}{c}\text { \% Energy Savings } \\
\text { Based on Brightness } \\
\text { Perception }\end{array}$ & $\begin{array}{c}\text { \% Energy Savings } \\
\text { Based on Visual } \\
\text { Acuity for Paper } \\
\text { Reading }\end{array}$ & $\begin{array}{c}\text { \% Energy Savings } \\
\text { Based on Visual } \\
\text { Acuity for } \\
\text { Computer Tasks }\end{array}$ \\
\hline $5.2 \%$ & $10.2 \%$ & $14 \%$ \\
\hline
\end{tabular}

Table 10. Visually effective lumens and efficiencies using the S/P ratio for $6 W$ LED

\begin{tabular}{|c|c|c|c|c|c|c|c|c|c|c|}
\hline \multirow{2}{*}{ No } & \multirow{2}{*}{$\begin{array}{c}P \\
(I m)\end{array}$} & \multirow{2}{*}{$\operatorname{Im} / W$} & \multirow{2}{*}{${ }^{0} K$} & \multirow{2}{*}{$S / P$} & \multicolumn{2}{|c|}{$P(S / P)^{0.5}$} & \multicolumn{2}{|c|}{$P(S / P)^{0.78}$} & \multicolumn{2}{|c|}{$P(S / P)$} \\
\hline & & & & & Im & $I m / W$ & Im & $\operatorname{Im} / W$ & Im & $\operatorname{Im} / W$ \\
\hline 1 & 545 & 91 & 4062 & 1.65 & 700 & 117 & 786 & 131 & 899 & 150 \\
\hline 2 & 640 & 107 & 5190 & 1.85 & 870 & 145 & 1034 & 172 & 1184 & 197 \\
\hline
\end{tabular}

Table 11. Percentage of potential energy savings comparing the led lamps no (2) to no (1) in table (10)

\begin{tabular}{|c|c|c|}
\hline $\begin{array}{c}\text { \% Energy Savings } \\
\text { Based on } \\
\text { Brightness } \\
\text { Perception }\end{array}$ & $\begin{array}{c}\text { \% Energy Savings } \\
\text { Based on Visual Acuity } \\
\text { for Paper Reading }\end{array}$ & $\begin{array}{c}\text { \% Energy Savings } \\
\text { Based on Visual Acuity } \\
\text { for Computer Tasks }\end{array}$ \\
\hline $19.3 \%$ & $23.8 \%$ & $23.9 \%$ \\
\hline
\end{tabular}

Tables 5 and 6 summarize the method model and the percentage of potential energy savings using VE lumen rating comparing $6 \mathrm{~W}$ LED bulbs (from table 6) have various CCTs specifically, the $5190{ }^{\circ} \mathrm{K}$ SEL demonstrates potential savings ranging from $19.3 \%$ to $23.9 \%$ as compared to $4062{ }^{\circ} \mathrm{K}$ bulb. 
Table 12. Visually effective lumens and efficiencies using the S/P ratio for $9 W$ LED

\begin{tabular}{|c|c|c|c|c|c|c|c|c|c|c|}
\hline \multirow{2}{*}{ No } & $\begin{array}{c}\boldsymbol{P} \\
\text { (Im) }\end{array}$ & \multirow{2}{*}{$\boldsymbol{I m} \boldsymbol{W}$} & \multirow{2}{*}{$\boldsymbol{K} \boldsymbol{K}$} & \multirow{2}{*}{$/ \boldsymbol{P}$} & \multicolumn{2}{|c|}{$\boldsymbol{P}(\mathbf{S} / \boldsymbol{P})^{\mathbf{0 . 5}}$} & \multicolumn{2}{|c|}{$\boldsymbol{P}(\mathbf{S} / \boldsymbol{P})^{0.78}$} & \multicolumn{2}{|c|}{$\boldsymbol{P}(\mathbf{S} / \boldsymbol{P})$} \\
\hline 1 & 998 & 111 & 4541 & 1.65 & 1282 & 142 & 1475 & 164 & 1647 & 183 \\
\hline 2 & 918 & 102 & 4870 & 1.73 & 1207 & 134 & 1408 & 156 & 1588 & 177 \\
\hline 3 & 901 & 100 & 4905 & 1.75 & 1192 & 132 & 1394 & 155 & 1577 & 175 \\
\hline 4 & 814 & 91 & 5717 & 1.85 & 1107 & 123 & 1315 & 146 & 1506 & 167 \\
\hline 5 & 905 & 101 & 6393 & 2.1 & 1312 & 146 & 1614 & 179 & 1901 & 211 \\
\hline
\end{tabular}

Table 13. Percentage of potential energy savings comparing the led lamp no (5) to lamps (1), ...,, (4) in table (10)

\begin{tabular}{|c|c|c|c|}
\hline No & $\begin{array}{c}\text { \% Energy } \\
\text { Savings Based } \\
\text { on Brightness } \\
\text { Perception }\end{array}$ & $\begin{array}{c}\text { \% Energy } \\
\text { Savings Based } \\
\text { on Visual } \\
\text { Acuity for Paper } \\
\text { Reading }\end{array}$ & $\begin{array}{c}\text { \% Energy Savings } \\
\text { Based on Visual } \\
\text { Acuity for Computer } \\
\text { Tasks }\end{array}$ \\
\hline 1 & $2.3 \%$ & $8.6 \%$ & $13.4 \%$ \\
\hline 2 & $8.0 \%$ & $12.8 \%$ & $16.5 \%$ \\
\hline 3 & $9.2 \%$ & $13.6 \%$ & $17.0 \%$ \\
\hline 4 & $15.6 \%$ & $18.5 \%$ & $20.8 \%$ \\
\hline
\end{tabular}

Tables 7 and 8 summarize the method model and the percentage of potential energy savings using VE lumen rating by comparing 9 W LED bulbs (from table 7) have various CCTs, specifically, the $6393{ }^{\circ} \mathrm{K}$ SEL demonstrates potential savings ranging from $2.3 \%$ to $13.4 \%$ as compared to $4541 \% \mathrm{~K}$ bulb, and through different CCTs until $15.6 \%$ to $20.8 \%$ as compared to the $5717 \% \mathrm{~K}$ bulb. Therefore, LEDs having different values for CCT, and higher S/P ratio, can be used to describe the effective lumens of indoor lighting. Using SEL, LEDs have achieved high energy savings by advocating the use of bluer lighting in commercial and municipal buildings.

\section{CONCLUSION}

Recently, LED lamps have become popular in lighting applications due to their energy savings and environmental compatibility. When used indoors, LED lights with a good S/P ratio can help reduce the wattage of lights, improve visual acuity and make indoor areas appear brighter and more attractive. SEL provides better visual acuity, enhanced brightness perception, and produces a light spectrum more closely resembling daylight. Therefore, the SEL can be used at lower energy levels while maintaining equal vision. LEDs having different values for CCT, and higher S/P ratio, can be used to describe the effective lumens of indoor lighting. Using SEL, LEDs have achieved high energy savings by advocating the use of bluer lighting in commercial, governmental and public buildings. 
By using the above method, the positive results, in this paper, are summarized in table 14 . Table 14 summarizes the results.

Table 14. The results

\begin{tabular}{|c|c|c|}
\hline LED rating & CCT (K) & $\begin{array}{c}\text { Potential energy } \\
\text { saving }\end{array}$ \\
\hline $4 \mathrm{~W}$ & 4100 compared to 2700 & $5.2 \%: 14 \%$ \\
\hline $6 \mathrm{~W}$ & 5190 compared to 4062 & $19.3 \%: 23.9 \%$ \\
\hline $9 \mathrm{~W}$ & 6393 compared to 5717 & $15.6 \%: 20.8 \%$ \\
\hline
\end{tabular}

\section{ACKNOWLEDGMENT}

A great deal of thanks is due to the UNDP/GEF funded project entitled "Improving Energy Efficiency for Lighting \& Building Appliances" in Egypt.

\section{REFERENCES}

[1] Berman, S.M Clear, R.D. Leon, "Past vision studies can support a novel human photoreceptor". CIE Midterm Meeting and International Lighting Congress. S.n, (2005).

[2] Berman, S.et al.2, "Luminance controlled pupil size affects landolt C test performance", Vol.22 (1993).

[3] Berman, S. et al, "Luminance controlled pupil size affects word reading accuracy", J.IES, (1995).

[4] Berman, S. et al.2, "Despite different wall colors, vertical scotopic illuminance predicats pupil size", Vol.26, (1996).

[5] Navvab, M.2, "A comparison of visual performance under high and low color temperature fluorescent lamps", Vol. 30, (200).

[6] Myledlightingguide.com. (2017). MyLEDLightingGuide: Commercial and Industrial LED Lighting. [online] Available at: http://www.myledlightingguide.com/ [Accessed 17 Dec. 2017].

[7] Eco-Revolution. (2017). Eco-Revolution. [online] Available at: http://ecorevolution.com/science-of-light/ [Accessed 17 Dec. 2017].

[8] S. Berman, "The re-engineering of lighting photometry," Journal if the Illuminating Energy Society.

[9] Office of Energy Efficiency and Renewable Energy, U.S Department of Energy, "Energy conservation using scotopically enhanced fluorescent lighting in an office environment". 
